
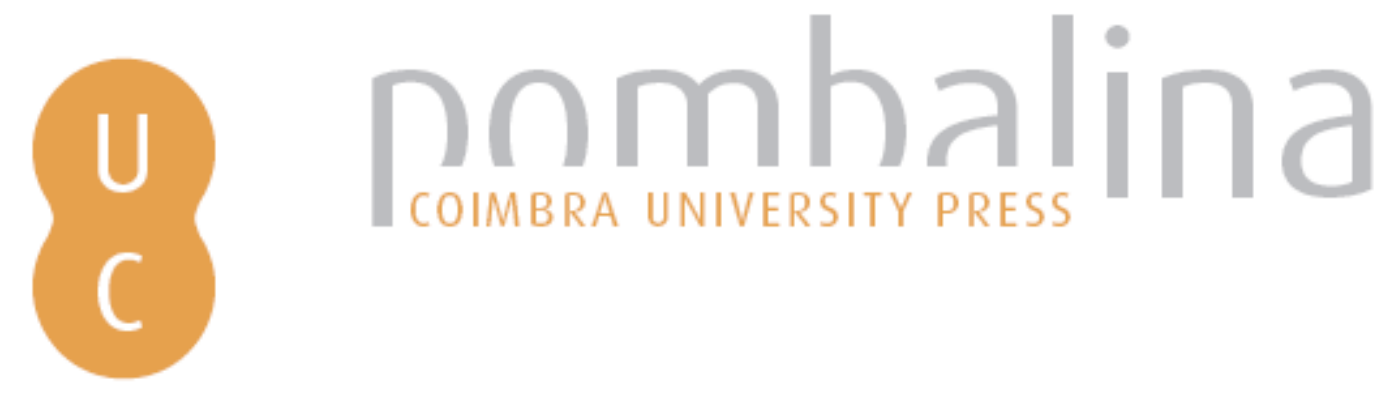

Safo no teatro espanhol contemporâneo: Entardecer em Mitilene de Andrés Pociña

Autor(es): Romero Mariscal, Lucía

Publicado por: Imprensa da Universidade de Coimbra

URL

persistente: URI:http://hdl.handle.net/10316.2/44262

DOI: $\quad$ DOl:https://doi.org/10.14195/978-989-26-1526-4_4

Accessed : $\quad$ 26-Apr-2023 11:03:35

A navegação consulta e descarregamento dos títulos inseridos nas Bibliotecas Digitais UC Digitalis, UC Pombalina e UC Impactum, pressupõem a aceitação plena e sem reservas dos Termos e Condições de Uso destas Bibliotecas Digitais, disponíveis em https://digitalis.uc.pt/pt-pt/termos.

Conforme exposto nos referidos Termos e Condições de Uso, o descarregamento de títulos de acesso restrito requer uma licença válida de autorização devendo o utilizador aceder ao(s) documento(s) a partir de um endereço de IP da instituição detentora da supramencionada licença.

Ao utilizador é apenas permitido o descarregamento para uso pessoal, pelo que o emprego do(s) título(s) descarregado(s) para outro fim, designadamente comercial, carece de autorização do respetivo autor ou editor da obra.

Na medida em que todas as obras da UC Digitalis se encontram protegidas pelo Código do Direito de Autor e Direitos Conexos e demais legislação aplicável, toda a cópia, parcial ou total, deste documento, nos casos em que é legalmente admitida, deverá conter ou fazer-se acompanhar por este aviso.

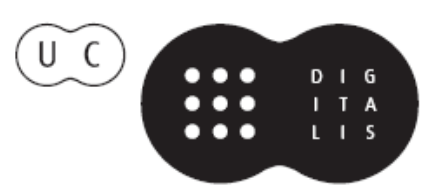




\section{MEDEIA, SAFO, ANTÍGONA}

\section{MITOS ETERNOS, NOVAS LEITURAS}

\section{ANDRÉS POCIÑA}




\title{
SAFO NO TEATRO ESPANHOL CONTEMPORÂNEO: ENTARDECER EM MITILENE DE ANDRÉS POCIÑA
}

\author{
Lucía Romero Mariscal \\ CySoc \& Universidad de Almería ${ }^{1}$
}

Entardecer en Mitilene, de Andrés Pociña, tem em muitos sentidos a beleza melancólica dos quadros banhados por uma luz vespertina. Representa, de facto, "o entardecer de um dia de verão que foi sufocante", mas, por outro lado, a Safo protagonista desta obra encontra-se também no entardecer de uma vida que teve, igualmente, os seus momentos acalorados ${ }^{2}$. Trata-se, sem dúvida, de um destino constante no teatro do autor, que dá a palavra a heroínas maduras que se entregam à memória dos dias passados, no caso da Medeia de Camariñas perante um auditório de mulheres que a censuram com o seu silêncio e displicência; no caso da Safo de Mitilene, diante de umas moças que adoram de uma forma ou de outra a sua mestra. O momento e o lugar em Entardecer em Mitilene são idóneos para a confidência e a intimidade femininas: uma vez suavizado o fulgor do sol estival, a luz filtrada da tarde faz com que cedamos ao repouso e que a nostalgia do dia, dos dias passados, nos recorde o que somos: o que vivemos e o que ainda queremos continuar a viver.

1 A obra Entardecer em Mitilene foi representada pelo Grupo Teatral Afrodite, sob a direção de Remedios Higueras, que atua como protagonista. Existe gravação filmada em DVD da representação de 27 de Abril de 2011 no Auditório da Universidade de Almería (Espanha). Estreada a 25 de Junho de 2010 na Universidade de Granada, até ao momento atual representou-se várias vezes em Granada (na Aula Magna de Filosofía y Letras, no Teatro Isidoro Máiquez e no Teatro Isabel la Católica), em Jaén (Universidade), em Almería (Universidade), em Coimbra (Museu Machado de Castro), e continua em programação viva. 2 Recorde-se, neste sentido, a monografia já clássica de DuBois 1995, intitulada, precisamente, Sappho is Burning, ou o artigo de West 1970. Ambos esses títulos fazem-se eco dos versos do Don Juan de Byron (3.86.1): "The Isles of Greece, the Isles of Greece/ / Where burning Sappho loved and sung." 
Desde o início se destaca a maturidade de Safo diante da juventude e leveza das moças que a rodeiam. As jovens vestem "túnicas frescas, compridas até meio da perna" e a sua imaturidade, a terna delicadeza da sua inocência, é simbolizada pelas cores claras, "muito claras", de cada um dos seus vestidos. Safo é a única que veste de branco, com a cor da pureza com que a saudara o poeta Alceu nos famosos e misteriosos versos do fr. 384 Voigt: "Entrançada de violetas, a pura Safo de sorriso de mel..."

As rubricas de cena dispõem, à maneira de tableaux, quadros onde o detalhe sobre as cores e a luz são precisos. Mitilene é uma povoação mediterrânica e a casa de Safo parece um pátio andaluz em que as mulheres conversam após as tarefas do dia. Os afazeres de Safo foram, sobretudo, as suas poesias. Depois saberemos que foi a primeira a levantar-se para comprar peixe no porto, mas no momento não nos parece estranho que se insista no facto de a poetisa ter estado todo o dia a trabalhar nos seus poemas com a meticulosidade que requer o ofício de compositora; além disso, preparou uma limonada e tem uma forte dor de cabeça.

A versão dramática de Entardecer em Mitilene não é, no entanto, uma recriação romântica nem idealizada da poetisa antiga. É certo que as alunas adoram a mestra e insistem, como o autor anónimo Do sublime, no afã de perfeição da poesia de Safo, que ela mesma corrobora como uma lição, quiçá a única, que se empenha em dar às suas discípulas. Safo leva a sério a elaboração da sua poesia, que trata de polir como um artista a sua obra. Mas a vivacidade da recriação dramática radica precisamente em que a própria vida entra em casa de Safo com tudo o que ela traz consigo: ciúmes, dissensões e até cansaço. Não sem um certo humor, Safo diz estar aborrecida com a sua própria poesia, pelo menos com os versos mais famosos que as moças, no entanto, não se cansam de recitar. E não só nos encontramos com uma Safo relutante em recitar os seus poemas, como também com uma aluna, Filénis, que reconhece com descaramento que não gosta nem dos versos da mestra nem da poesia dos grandes poetas, como Homero; inclusivamente encontramos uma amada que declara à amante, com palavras grosseiras, que está farta dos seus versos. Estamos, pois, diante de uma reelaboração muito original na história da tradição clássica e da receção.

Contudo, o mundo subtil e deliciosamente refinado da poesia de Safo permanece. O meio teatral proporciona um quadro que permite fazer dos versos a verdadeira figura do drama, ao concentrar a atenção e a inteligência do auditório sobre eles. Trata-se, assim, de uma recriação cuja vivacidade nos adverte da ressonância da poesia de Safo, da sua paixão amorosa, da sua sensibilidade face à beleza, e por tudo isso, da sua dor e deceção por não ser justamente correspondida.

O primeiro auditório da poesia de Safo está, no entanto, dentro da própria obra. Mesmo se cada moça tem nome e personalidade própria, a peça tem algo de um jogo 
coral na comunidade que elas constituem como alunas de Safo. Nelas observamos os primeiros efeitos da poesia sáfica, que se expõe aos ciúmes e rivalidades numa aprovação comum da beleza. Mas, como boa mestra -e talvez Máximo de Tiro não estivesse tão errado ao comparar Sócrates com Safo- esta não se compraz tanto em ser escutada como em escutar as composições que as alunas produzem por si próprias. Ante o estímulo erótico da beleza poética, as moças irão responder unindo-se a ela e dando à luz novos versos. Safo recita uma estrofe própria e incita as jovens a que continuem. Este jogo poético irá estender-se ao longo de toda a obra, intercalada com recitações e cantos, quer da poetisa antiga, quer novas composições, como se o próprio autor recebesse este incentivo da mestra e por sua vez lhe respondesse.

Andrés Pociña revela-se seguidor de Safo restituindo, através desse ensino, uma poesia sem fissuras, apesar do seu estado fragmentário. O primeiro exemplo produz-se a propósito dos famosos versos do fr. 168B Voigt, de que o autor produz uma formosa tradução: "Ya se ha puesto la luna / y las Pléyades; mediada es / la noche, pasando va la hora / y yo me estoy durmiendo sola". Após o intento falhado de Mégara, que, para irritação da mestra, não pode evitar recitar outra estrofe de Safo, a correspondente ao fr. 34 Voigt $^{3}$, Irana pronuncia a estrofe do que poderia ter sido um dos epitalâmios da autora. Os novos versos elaboram imagens próprias da poética sáfica, como o desejo erótico feminino ou a própria feminilidade relacionada com o mundo vegetal, ao mesmo tempo que preservam e evocam algumas das fórmulas tradicionais que a própria Safo empregara para os cantos de boda, como a comparação do noivo com o amante de Afrodite, o deus Ares ${ }^{4}$. Mais adiante, Irana voltará a cantar um epitalâmio especialmente composto para outra das suas companheiras, Girina. Este canto, uma espécie de seguidilha muito apropriada ao padrão folclórico do poema nupcial, partilha totalmente do universo poético de Safo, rico em variedades florais, voluptuoso

3 Também em tradução de Andrés Pociña: "Las estrellas en torno de la hermosa luna / de nuevo esconden su resplandor / cuando en su plenitud llena ilumina / la tierra entera..."

4 "Mas espero el alba rosada / para distinguir en el horizonte / tu enjuta escultura, / amor de músculos recios, / fuerte al caminar cual Ares, / ondeando al céfiro tus bucles / y en tu mano para mí una rosa». Note-se, por exemplo, que a moça inicia a sua composição com uma das fórmulas poéticas que Safo emprega, por exemplo, no fr. 16, em conformidade com a tradição homérica. Mais adiante a própria Safo recitará o fr. 111 Voigt correspondente a um epitalâmio e que Andrés Pociña traduz assim: "Arriba la viga maestra, / ¡hurra! / alzadla, carpinteros, / ¡hurra! / El novio entra, igual que Ares, / ¡hurra! / mucho más alto que un hombre alto / ¡hurra!”. 
em adornos e telas ${ }^{5}$. Ao colocar, nesta ocasião, a mulher no centro do poema, merece a aprovação da mestra, que antes tinha recordado às discípulas: "É preciso retornar de novo a nós mesmas. Antes de nada a nós mesmas" ${ }^{* 6}$.

Entardecer em Mitilene devolve-nos precisamente Safo e o seu círculo. Há, no entanto, que fazer distinções. Não se trata de insistir na tão badalada Sapphofrage. A Safo de Andrés Pociña é bastante ciosa da sua intimidade. Com autoridade diz a uma das alunas: "Não te permito que te metas nos meus assuntos íntimos, que não te interessam em absoluto". É uma advertência que faz a toda a gente. A novidade desta versão dramática assenta na própria representação da poesia de Safo no meio vital da sua composição.

Arriscar-se a dar um meio vital à poesia de Safo é, verdadeiramente, uma façanha dramatúrgica. Por isso, o autor recriou uma Mitilene com delicados tons antigos ou arqueológicos que, mesmo quando destacam a sua singularidade grega, não se nos apresentam como um passado alienado. Os juramentos por Afrodite, a deusa mais recorrentemente invocada e celebrada nos fragmentos conservados, assim como os cantos em língua grega, mesmo se moderna, contribuem para este efeito de helenização que nos é facilmente reconhecível, sem que o público não especialista o sinta como excessivamente extranho. Do mesmo modo, a modernidade da linguagem usada em prosa, unida aos jogos poéticos das traduções e composições líricas, com marcados ecos da nossa tradição clássica hispânica, colaboram com um ambiente atemporal e mediterrânico em que penetramos facilmente.

Há nos versos de Andrés Pociña ecos de Frederico García Lorca e do neopopularismo de 27; é possível reconhecer também alguma evocação da sua querida Rosalía de Castro? $^{7}$ e, desde logo, é impossível não perceber uma intertextualidade garcilasiana na expressão "antes de que el paso del tiempo esparza por tus cabellos una nevada

5 «Ciñe la tierna novia / rubia melena / con rosas, margaritas / y violetas. / Cuidad vientos marinos / la niña bella. // Cubre la tierna novia / su terso pecho / con sedas orientales / y aderezos. / Llévala con cuidado / feliz barquero. // Muestra la tierna novia / su hermoso seno / fragante de jazmines / y de eneldo. / Tócala con ternura / novio trigueño». Uma das imagens recorrentes do erotismo feminino em Safo é, desde logo, o peito da amada, como se vê no fragmento 30 Voigt, um epitalâmio onde se fala do peito de violetas da noiva. Cf. também os frs. 21 e 103, em que aparece igualmente o epíteto feminino referido ao peito de violetas, ou o fr. 126.

6 Como assinalou Wilson (1996) 14, no mundo poético de Safo são os homens, e não as mulheres, quem representa o 'outro'.

Importa referir aqui não só as afinidades de sensibilidade com o meio natural e a noite ou a alvorada, assim como com os cantos populares, como também, de uma maneira 
perenne", nos lábios da própria Safo. Por sua vez, o autor reelabora no momento mais íntimo e profundo da obra uma narração breve que ele mesmo publicara em galego, "Solpor (Safo de Lesbos, 596 a.C.)", em Quince mulleres, quince momentos (A Coruña, 2000), de que existe tradução em castelhano ("Safo", En Grecia y Roma III: Mujeres reales y ficticias, Granada, 2009).

Trata-se, com efeito, de um momento de especial intensidade dramática, destacada cenicamente pelo movimento coral das moças que rodeiam a mestra, constituindo literalmente uma imagem representativa do círculo de Safo. A rubrica de cena sublinha além disso a centralidade da mestra mediante um emprego dramatúrgico da luz, que deixa na penumbra as discípulas ao mesmo tempo que o rosto de Safo fica iluminado. É como se a própria Safo fosse essa lua dos seus poemas que brilha na obscuridade da noite rodeada de estrelas. Tem então lugar um monólogo narrativo-recitativo em que a poetisa conta a sua triste história de amor com Átis. Este monólogo está cruzado de alusões subtis a fragmentos conservados de Safo e a todo o seu mundo poético, um mundo de intimidades de lua e de paixão erótica, mas também de solidão, de recordações e despedidas.

Este momento vem precedido por uma alusão velada das alunas a esta história de amor de que souberam extrair um modelo, mesmo se doloroso. O amor entre mulheres é tão intenso e verdadeiro como entre homem e mulher: "Onde está escrito que não pode querer, amar, gozar, uma mulher com uma mulher, ou um homem com um homem? A nossa mestra sabe-o bem". A Safo de Andrés Pociña é, sem dúvida alguma, a Safo das Tristias de Ovídio, cujos ensinamentos poéticos são os do amor. Assim o disse antes Irana à própria Safo: "Sei muito bem o que é o amor, porque tu nos deste as chaves precisas para o reconhecer. Aprendi-as bem" ${ }^{\text {. }}$ Essas chaves são, precisamente, as dos males de amor, as do sofrimento amoroso padecido pela pessoa que se sente excluída numa relação que deixou de ser bilateral, como se via no famoso fr. 31 Voigt recitado pela moça.

Mas a delicadeza das alunas leva-as ao extremo de supor que a mestra quererá esquecer a experiência sempre lacerante do amor não correspondido. A resposta de Safo a Telesipa é determinante neste sentido e expressa-se em consonância com a exortação à memória dos tempos felizes do passado que se vê, por exemplo, nos versos do fr. 94 Voigt, quando Safo se despede de Anactória. Naquele poema Safo queria morrer pela dor da despedida de Anactória, que a deixava, como a própria moça confessara, contra

mais ousada, com a sensibilidade social, quase combativa, que manifesta a Safo do final da obra, algo que, desde logo, não conhecemos pela Safo documentável.

$8 \quad$ Irana confirma assim a interrogação retórica do Ovídio de Tristias II 365: Lesbia quid docuit Sappho, nisi amare, puellas? ("¿Que ensinou a lésbia Safo às suas meninas, se não a amar?"). 
a sua vontade . A Safo de Andrés Pociña adopta o mesmo método de consolação pela memória, neste caso ainda mais dolorosa pois Átis deixará a sua amante por vontade própria. Orgulhosa e madura, esta Safo declara: "Não estou a tratar de esquecê-lo, porque foi um amor muito bonito, não vou negá-lo, e não houve nada de cuja recordação me envergonhe, ou de que tenha de arrepender-me".

A pedido das moças, Safo conta a sua história. A princípio a mestra reage às confidências: "É algo muito meu, não creio que vos interesse"; mas perante os rogos das discípulas, cede. O momento dramático cresceu em intensidade por esta renúncia que ameaçou o interesse das moças, e o nosso próprio, de aprender "a versão autêntica" dos lábios da mestra. Mas Safo contará a sua história numa intimidade feminina que parece evocar os formosos versos do fr. 160 Voigt: "Estas delicadas coisas cantarei agora para as minhas companheiras".

A história que Safo conta é uma recriação de alguns fragmentos conservados da autora, entrelaçados na narração de um modo coerente e nada artificioso. Como todo o exercício pessoal da memória tem, naturalmente, os seus meandros e divagações, os seus saltos e interrupções, e até diferentes tons de emoção-desde o mais nostálgico ao mais iracundo- e de expressão -desde a mais lírica à mais crua. Os fragmentos integram-se neste fluir da memória, quer mediante a recitação direta, quer mediante a alusão indireta.

O primeiro fragmento recitado em cena, "em voz muito baixa", é uma espécie de melodia que acompanha por um instante o relato de Safo. Pronuncia-o uma das suas alunas, Mégara, que reconhece nesta versão agora revelada pela mestra versões anteriores que aprendeu de memória. Safo adere à recitação da jovem e repete o segundo verso do fr. 49 Voigt: "Pequena me parecias e desengraçada". O público familiarizado com a poesia de Safo pode suprir perfeitamente o primeiro verso, dado que todo o relato de Safo vem marcado de alguma forma por ele: Eu amei-te, Átis, há algum tempo... ${ }^{10}$

Safo descreve a beleza de Átis desde a primeira impressão de menina pequena e sem muita graça que a princípio lhe tinha produzido, até ao conhecimento exato que a observação inequívoca do amor logo lhe proporcionara. Átis "não era nenhuma beleza, nem pouco mais ou menos"11. Quem sabe se não há aqui, aliás, uma subtil alusão àquela tradição que fazia da própria Safo uma mulher pouco esbelta, baixita e morena, que

9 Nem todos os editores atribuem o desejo de morrer a Safo, como o faz, por exemplo, Ferrari (2004).

10 Seguimos a edição que une estes dois versos num mesmo fragmento, se bem que não consecutivamente.

11 A Átis de Andrés Pociña parece devedora da imagem que dela fizera Fernández Galiano (1958), cuja monografia sobre Safo foi muito apreciada dentro e fora de Espanha. 
soube apreciar a beleza como os melhores poetas ${ }^{12}$. Desde logo, a Safo de Andrés Pociña sabe apreciar a beleza dos olhos, os lábios, os dentes, as mãos, e, claro, o peito de Átis, especialmente da Átis que viveu em sua casa e não da Átis pouco polida que foi viver com Andrómeda. A indignação ante o espectáculo grotesco dessa nova Átis, depois da transformação, é o que motiva a recitação de outros versos, os correspondentes ao fr. 57 Voigt, que, segundo a Safo de Andrés Pociña, foram escritos "pensando em Andrómeda": "Quem é essa tosca que te embruxa os sentimentos, Átis, que de tosca leva o vestido e os colares, e não sabe arrastar uns farrapos sobre os tornozelos?".

Mas o certo é que a Átis do passado fez Safo enamorar-se perdidamente. A descrição deste amor é reconhecível por qualquer pessoa que tenha estado enamorada alguma vez, mas é também uma experiência amorosa que a própria Safo canta em vários fragmentos da sua poesia e muito especialmente num em que se menciona expressamente Átis. A Safo de Andrés Pociña diz que "não deixava de pensar nela, de manhã, à tarde e à noite". A Safo antiga parece consolar uma Átis entristecida pela partida de uma amiga imaginando uma reciprocidade de sentimentos, de modo que essa mesma amiga não pode deixar de pensar também em Átis. A amiga está em Sardes, mas, segundo se lê no v. 2 do fr. 96 Voigt: "muitas vezes tem aqui o pensamento"; e nos vv. 15-17 acrescenta: "e muito vai e vem, levando na memória a doce Átis e de desejo se lhe consomem as entranhas"13. Outro fragmento, desta vez na primeira pessoa do singular, fala também desta obsessão amorosa, como de uma loucura que, apesar de tudo, refresca a mente que ardia de desejo: "Chegaste e eu por ti enlouqueci; refrescaste a minha mente que ardia de desejo"14.

Safo rememora os momentos felizes da sua união amorosa com Átis. A confidência abre-se a recriações poéticas de um marcado erotismo ${ }^{15}$. Também é possível reconhecer nelas ecos de Safo e algumas das fórmulas poéticas que ornamentam a sua poesia,

12 Fernández Galiano destaca que a Safo antiga antepõe à beleza física a "formosura de uma mente soberana". Também a Safo de Andrés Pociña defende a inteligência de Átis: "Não estou de acordo com isso que dizes, Mégara: Átis não era nenhuma imbecil. Não, qual quê! De imbecil não tinha mesmo nada. Tinha um encanto divino, e eu amei-a de verdade". 13 Como assinala Lardinois (1996) 150-172, deve tratar-se de um poema bastante longo, de pelo menos 40 versos, em que se celebrava a beleza de Átis. O poema tem um marcado tom coral e devemos imaginar a moça que está na Lídia bailando num coro local, mas pensando em Átis e nos cantos e danças que com ela partilhara no passado.

14 Fr. 48 Voigt.

15 A iniciativa erótica feminina é uma das inovações poéticas de Safo, caraterística, por outro lado, da sua poesia. A experiência erótica feminina é expressa na poesia de Safo como uma relação de reciprocidade e igualdade, embora não duradoira dado que há-de 
como "a chegada da Aurora de sandálias douradas", que evoca precisamente o último verso de um possível epitalâmio conservado no fr. 103 Voigt, "a Aurora de sandálias de ouro", ou no único verso conservado do fr. 123 Voigt, "há um momento, a Aurora de sandálias de ouro ..."

Chegada ao auge deste clímax poético, a memória de Safo dá lugar ao relato do seu progressivo desmoronamento. Esta Safo madura e experimentada é a mesma Safo do fragmento que encabeça todas as edições da poetisa antiga, aquela que com fé ou ironia suplicava à deusa do amor, Afrodite, que lhe fosse propícia na façanha heróica da conquista amorosa. Quando a Safo de Andrés Pociña diz "Mas Afrodite deixou de escutar as minhas preces e de ser-me propícia demasiado cedo", não podemos deixar de recordar, pelo contrário, aqueles versos em que a Safo antiga invocara, numa espécie de prece, à maneira de mágico sortilégio, o favor de Afrodite como sua aliada ${ }^{16}$.

Átis é corrompida pelas maquinações de Andrómeda e Safo perde a batalha. De novo a alusão velada à despedida de Anactória serve para contrastar a diferença com a despedida de Átis. É verdade que de nada serviu "que lhe recordasse os belíssimos momentos que tínhamos passado juntas", algo a que exortara a Safo antiga no doloroso momento da despedida de Anactória, como se lê nos mal conservados vv. 9-11 do já citado fr. 94 Voigt: "Mas se não, a ti quero recordar ... e as coisas boas que passámos"17. Mas, de facto, de nada serviram nem a recordação do passado feliz nem as perspetivas despudoradamente realistas do futuro. Porque esta nova Safo acrescenta às razões da amante as razões da mulher culta e intelectualmente madura, que não são outras senão a preocupação pela sua formação. Em breve veremos que esta será a marca de identidade da imagem feminista com que o autor representa Safo neste Entardecer em Mitilene.

A Safo do passado disse: "Átis, aborrece-te pensar em mim, e voas para Andrómeda"18. Este aborrecimento é explicitamente citado pela Safo de Andrés Pociña, que tem de recordar com tristeza e humilhação as cruéis e sórdidas palavras de desprezo de Átis.

confrontar-se com a separação das amantes. Cf., neste sentido, os trabalhos correspondentes de Stehle e Skinner (1996) 149 e 186.

16 Recorde-se, neste sentido, o artigo de Segal (1974). Cf., também, Carvalho (2012) Capítulo I.

17 Como assinala Luque (2008) 87-136, a memória é para Safo o lugar das experiências eróticas partilhadas.

18 Fr. 131 Voigt. É possível que este fragmento fosse a continuação do famoso fr. 130, em que se fala do desejo amoroso como de um dulceamargo animal inmanejable. A Safo de Andrés Pociña assinala precisamente esta transformação da doçura da união amorosa na amargura de uma separação que não pôde evitar-se. 
O momento é tanto mais doloroso quanto sabemos da finura e elegância de Safo, que já corrigiu em mais de uma ocasião a sua aluna Filénis por ouvi-la expressar-se numa linguagem inadequada. Esta Safo distinta e aristocrática terá de ouvir dos lábios da sua amada "palavras nunca antes ouvidas por mim". À tristeza junta-se, no entanto, a indignação, de modo que o famoso fr. 55 Voigt se entende agora muito melhor; e mais ainda quando esta Safo reconhece que, à tristeza e à vergonha, se une o augúrio ominoso do deletério efeito de "afastar-se para sempre da poesia", i.e. deixar de participar das rosas de Piéria. A tradução deste fragmento, tomada da poetisa Aurora Luque, merece citação: "E morta hás-de jazer, e não haverá de ti memória um dia, nunca, no tempo que há-de vir; porque não participas das rosas da Piéria; mas, invisível até na mansão de Hades, irás errante entre apagados mortos, caída do teu voo".

Andrés Pociña é sensível à dureza destes versos, e por isso faz a sua autora confessar: "Arrependi-me de lhe ter escrito uma coisa tão cruel, mas custou-me muito recuperar-me, começar a esquecê-la".

Safo singulariza a história de Átis pela tristeza do fracasso não só amoroso mas também pedagógico. A mestra confessa o seu desvelo amoroso por todas as alunas e a dor pela despedida de cada uma delas, com quem trava um vínculo afetivo difícil de romper. "Mas a causa é formosa", como acrescenta a poetisa. "A partida de Átis, por seu lado, é talvez a história mais triste da minha vida". E com esta confissão fica no ar "um silêncio comedido, total, de que não sabem como sair, nem o que dizer". O coro de raparigas ficou emudecido ante tão triste revelação. Será a própria Safo quem rompe o ambiente de pesar que se criou e fá-lo com palavras que não são senão a oportuna tradução dramática de outro fragmento em que a Safo do passado recordava que " não é permitido que haja dor em casa de quem serve as Musas ... inconveniente seria para nós”19.

Estimuladas pela mestra, as moças envolvem-se de novo numa discussão àcerca do amor e de Átis, claro. Safo, conciliadora, volta a insistir no baluarte da educação. O maior defeito de Andrómeda, a corruptora de Átis, "reside na sua terrível ignorância, na sua carência absoluta de qualquer tipo de educação”. A tradição clássica derivada das notícias antigas que faziam de Andrómeda plausivelmente uma rival de Safo na competência educativa fica aqui drasticamente transformada. A pureza ou a prudência de Safo cala o que as desenvoltas alunas destacam com franqueza: que Andrómeda prostituiu literalmente o seu ascendente sobre as pupilas ${ }^{20}$.

\section{Fr. 150 Voigt.}

20 Sobre a rivalidade "educadora e amante" de Safo com Andrómeda e Gorgo, cf. o fr. 32 Voigt e o seu comentário em De Martino \& Vox (1996) 1029; assim como Fernández Galiano (1958) 24-27. 
Mas as moças ficaram impressionadas com a confissão do vínculo amoroso que se trava inevitavelmente em casa de Safo e que, contudo, está destinado a desfazer-se por uma separação dolorosa. Como espetadoras sensíveis, sabem que a história de Safo pode ser também a sua própria história. Gôngila, de facto, deixa escapar umas lágrimas que são a expressão do seu próprio temor de sofrer algo parecido em relação a Telesipa, de quem está enamorada e por quem é correspondida. Também a separação de Gôngila e Telesipa parece inevitável.

Tem lugar então uma quebra inesperada no desenlace da obra, que gradualmente vai adaptando a pessoa de Safo à figura que a tradição posterior e a história recente da receção foram configurando e que Andrés Pociña resumira na sua imagem particular da poetisa em Tecer con palabras. Mulleres na poesía en catalán, galego e portugués (Santiago de Compostela, 2007). Aí, o autor dizia que, sobretudo a partir do século XIX, Safo se converte na "mãe universal" das mulheres poetas. Gôngila e Telesipa hão-de sê-lo, como o público mais ou menos familiarizado com a cultura grega sabe, especialmente no caso da segunda. A surpresa está em que seja precisamente Filénis, a menos poética das alunas de Safo, quem tem a ideia de que a mestra adote como filhas as discípulas enamoradas e as salve assim de uma separação dolorosa. Ao ficar com Safo para sempre, as moças são integradas de pleno direito na casa das servas das Musas e o labor poético e instrutivo perpetua-se. A ideia não pode ser mais feliz nem mais generosa, como sublinha Safo genuinamente comovida.

Resta ainda uma última surpresa, porque esta Safo "mãe universal" tem de expandir a sua descendência no espaço e no tempo. Quando as moças estão tão contentes, celebrando em coro, cantando e bailando em grego, a feliz ocorrência de Filénis, Safo "rompe em soluços", levada agora pela memória mais próxima de um espetáculo tristíssimo que contemplara ao amanhecer e que contrasta com o belo espetáculo das discípulas neste entardecer tão quente. Interrogada pelas alunas, a mestra fala-lhes do barco que viu de manhã no porto, carregado de mulheres negras escravas. Todas concordam na repulsa perante a escravidão, mas concordam também na impotência para mudar um mundo que igualmente as subestima. "Nós as mulheres nunca podemos fazer nada", diz Irana. Safo, que concorda um tanto distraída a princípio, "triste, reflexiva", replica então com a força do que já vimos ser a sua maior convicção: "Claro que sim! Por exemplo, podemos discordar. E podemos preparar-nos, cada vez mais, cada vez melhor, para o dia em que possamos fazer alguma coisa”.

Esta preparação é, sem dúvida alguma, a que a educação proporciona. Foram, desde logo, as mulheres, ao preparar-se cada vez mais e melhor, quem tornou possível esse dia. Ainda há muito por conseguir, mas Safo ficaria verdadeiramente agradada se tivesse visto o que conseguiram fazer tantas mulheres seguidoras das suas palavras, 
suas discípulas, suas filhas. Convém assinalar, de resto, que a educação a que se refere Safo é, sobretudo, uma educação poética. A educação poética é a que permite, com efeito, desenvolver capacidades imaginativas e críticas que favorecem o florescimento e o cultivo do humano. Esta lição de Safo não deveria menosprezar-se num mundo como o nosso em que as humanidades vão sendo cada vez mais postas de lado em prol do economicamente rentável e de uma desejada utilidade prática e científico-técnica que nem sempre tem o ser humano como seu fim imediato.

Ao longo da obra, Safo insiste no seu papel de educadora. Também as alunas reconhecem que o sentido da sua pertença ao círculo de Safo é a educação artística, o refinamento cultural. A própria Filénis o afirma com consciência de classe, apesar das suas reticências estéticas não só em relação com a poesia épica e a sua violência bélica, mas também com a poesia amorosa que ela considera menos genuinamente sáfica, como a que tem a ver com Fáon ${ }^{21}$. Impõe-se, pois, a tradição clássica que, a partir dos testemunhos conservados, valoriza Safo como mulher educadora, um labor que no mundo antigo é próprio dos poetas e de que Safo tinha feito duplamente profissão ${ }^{22}$.

A Safo de Entardecer em Mitilene mostra, além disso, uma inquietude social provavelmente alheia à Safo do passado, embora conserve o seu caráter aristocrático e um mesmo orgulho caraterístico ${ }^{23}$. O final da obra é, de facto, soberbo neste sentido. A mestra despede as discípulas e manda-as cear e recolher-se. Chega então o porteiro e aguarda as ordens da senhora da casa. Safo cumpre o seu papel e dá-lhe instruções sobre algumas tarefas domésticas e algo mais. Sabe que o jovem tem tido demasiadas liberdades com a atrevida Filénis, pelo que lhe ordena que vá também para a cama e antiga, de uma Safo que morre de amor por Fáon, e salva-a por via exegético-alegórica do exemplum a contrario. A própria Safo tem de reconhecer que não deixam de surpreendêla as interpretações da jovem que, há que sublinhá-lo, é a única cujo nome próprio não figura nos poemas nem nos testemunhos transmitidos da autora. Este afastamento da tradição ovidiana, a mais influente, como assinalara Most (1996) 17-18, na história da receção de Safo, é mais uma prova da originalidade de Entardecer em Mitilene.

22 Andrés Pociña segue também as linhas da recente e rigorosa filologia italiana, especialmente clara na introdução a cargo de Vincenzo Di Benedetto (2004) e de De Martino e Vox (1996). Contrária a esta tradição seria a daqueles que questionam tanto a suposta escola de Safo como a sua congregação cultual ou thíasos, uma posição resumida em Parker (1996) 146-183. 
com uma eloquente subtileza termina: "Amanhã de manhã temos de ter uma conversa. Há regras que não podem quebrar-se de nenhum modo na casa de Safo de Mitilene" 24 .

É difícil não sentir certa ironia neste solene final que reduz o homem ao silêncio e ao assentimento. De facto, não houve uma só intervenção masculina em toda a obra, e agora que aparece o único personagem homem, não abre a boca ${ }^{25}$. Com Entardecer em Mitilene, Andrés Pociña conseguiu, assim, uma espécie de justiça poética ao dar à mulher a última palavra.

24 Estas palavras finais de Safo são especialmente felizes pela exatidão da recriação da casa. Assim, tal como assinalam De Martino e Vox (1996) 1028-1019, "Si è parlato di tiaso, di scuola, di circolo, ma forse basta parlare di oikos o domos, tanto più che lei stessa parla di 'casa delle ministre delle Muse' (F 150)”. Cf. também Fernández Galiano (1958) 17. 25 Como assinalou $\mathrm{M}^{\mathrm{a}}$ de Fátima Silva no prólogo às edições portuguesa e galega, esta personagem não tem sequer um nome, o que contrasta com o resto das personagens femininas tão singularmente caraterizadas e com nome próprio. 